\title{
State-of-the-Art Technique to Appraise the Quality of Piling
}

\author{
W. J.B. Shiroma! Fernando and R.Thivakar
}

\begin{abstract}
The construction industry in Sri Lanka has seen a boom in the past two decades. The promising construction industry does not fail to endow a number of high-rise buildings in and around the commercial capital, Colombo. Due to the soil conditions, building loads, resource availability etc., Geotechnical experts quite often recommend bored and cast-in-situ pile as the deep foundation of choice in such high-rise buildings. However, the quality assurance systems for piling have not developed on a par with the increasing piling construction works. The cost and time are the major factors that set constraints against maintaining high quality assurance standards in any project. The selection of piles for testing has been the critical aspect in determining the cost and time of the quality assurance system. In this technique, scores were assigned to various aspects such as boring method, boring equipment, de-sanding method, flushing method, duration of borehole kept open before concreting, quality of the concrete, concreting method, cube strength of concrete, concrete wastage, pile integrity, etc. These scores have different weightings based on their individual importance. The piles scoring above a preset score would be selected for dynamic testing. The devised method to select piles for dynamic testing has proven extremely effective and efficient. The outcomes from the adopted quality assessment system had accentuated the importance of keeping track of the quality of each and every pile from the preconstruction stage itself.
\end{abstract}

Key words: Piling, Quality assurance, PDA, PIT, SLT, Fuzzy logic

\section{Introduction}

The booming construction industry in Sri Lanka has endowed many high-rise buildings in and around the commercial capital, Colombo. There are a number of proposed high-rise projects in progress presently and others in tk pipeline to be commenced; awaiting a positive gesture from the economic indicators of the country. Highrise buildings, over 20 stories, are most likely to be supported by deep foundations like piles. Due to the sub-soil conditions, building loads, availability of resources etc., Geotechnical experts quite often recommend bored and castin-situ piles as the deep foundation of choice for such high=rise buildings. Increasing construction activities have caused the stakeholders of construction to resort to new methodologies and techniques of construction as opposed to conventional tested- and- true procedures. The construction of piles is a very important exercise as the failure of a pile would cost the owner millions to reinstate the building.

Therefore, the construction processes ought to be monitored and controlled in every step of the way to avoid such failures. Even though there are a number of methods available to construct bored and cast-in-situ piles, such as (a) Uncased Drilling Method- Hole Stabilized by Slurry (bored and cast in-situ), (b) Fully cased Drilling with Rotary Drive, (c) Drilling with Continuous Flight Augur, (d) Fully Cased Drilling Oscillator, (e) Drilling with Displacement System, (f) Drilling with Fixed Double Rotary Drives, (g) Mixed-in-Place System with Triple Auger, (h) Drilling with Movable Double Rotary Drives, etc., yet method (a) is the common method being adopted in Sri Lanka. Thus, Uncased Drilling Method is the method examines in this paper.

Major steps involved in the construction of bored and cast-in-situ piles using Uncased

E11g. W.J.B.S/iro111al Fernando, BSC. Eng (Hons), CEng, MIE (SL) He is presently toorkii,g at Design Consortium Limited as Director cum Senior Structural Engineer. He has vast experience lil the design of lugh rise buildings lil Sri Lanka. He is an honorary Secretary of the Socl'etyof Structural Engineers, Sn'Lanka since 2005. He is reading for his MPhil under the superuision ofProf WP.S.Dias. He has conducted a number of short courses at ICTAD and University ofMoratuwa in his field of specialization.

R. Thiuakar, BSc. Eng (Hons\}, MSc. (Strucf. Eng.\}, MBA (Business Management\}, ACS. He is worklilg al Design Consortium Limited as Structural Engineer since 2006. He has workedas Research Assistant at the University of'Moratuto under the guidance ofProf W.P.SDias and Dr.SMSN Nanaykkara after his graduation. He success. folly completed the Master's programme in Structural Engineenitg $1 ! 1$ the University of Moraturoa in 2006 and the Business Administration Course $111 / C B S$, affiliated to Warnborough University, UK, 1112005 He is $11 ! !$ Associate member of the Society of Structural Engineers, Sri Lanka. 
Drilling Method are: (a) Installation of top casing with rotary drive of the drill rig, (b) Excavation of soil with the drill bucket and stabilization of the bore hole with slurry (bentonite or polymer), (c) Cleaning the slurry with the de-sander or flushing, (d) Installation of reinforcement cage, (e) Pouring of concrete with the tremie pipe while pumping back the slurry to the tank, and finally (f) extraction of the top casing with the rotary drive of the rig (Fig.1) [1]. In order to produce a flawless pile, the quality assurance and quality control (QA/QC) system shall be in place to monitor and control the factors involved with the above method during the process of the construction. In the absence of a proper QA/QC system it is reckoned that an unacceptable number of piles could fail to achieve the design pile load capacities. The piles found to have failed to mobilize the required design load are most probably replaced with compensatory piles as per the present practice in Sri Lanka. Since the piles, which have failed, remain unused in the ground they could be termed as "dead piles".

This paper primarily discusses a novel technique of evaluating and assuring the quality of piling works with limited time and cost that set constraints against maintaining high quality assurance standards in any project, the method of construction of piles and the available methods of testing the same.

The selection of piles for testing has been the critical aspect in determining the cost and time involved in a quality assurance system. The method discussed in this paper has been tested and proven to be successful in one of the largest building projects in Sri Lanka. The method essentially used a scoring technique using the fuzzy logic techniques.

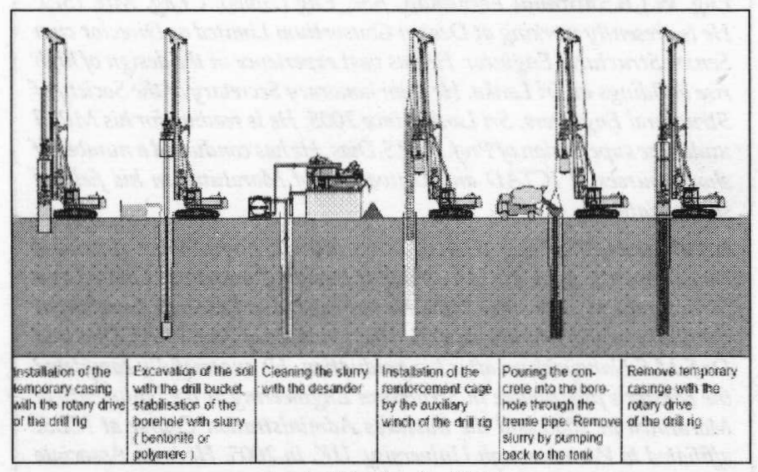

Figure1: Typical Pile installation sequence
In this technique, scores were assigned to various aspects given under the generalized titles such as "Quality of Drilling Machines and Drilling Tools", "Quality of Rock Socketing", Quality of Maintaining Borehole, "Quality of Cleaning the Borehole", Quality of Concreting, "Integrity of the Pile", etc. These scores have different weighting limits, which can be adjusted at the discretion of the Engineer, set by the authors based on their individual importance. The aggregate of assigned scores is used to check against a preset value and if the aggregate is found to be greater than the preset value then the pile is subjected to testing.

\section{Considerations in Design of Piles}

A good foundation design requires a sound understanding of the local soils and rocks. As a preliminary, it is advantageous to collect information relating to the site prior to the commencement of design. The details that are available from records and maps relating to geological information should be studied and advantage should be taken of existing site investigation results and local knowledge [2] The ground exploration is generally carried to a depth which includes all strata likely to be significantly affected by the structural load and the construction operations. The depth of exploration depends on the type of structure, the size, shape and disposition of the loaded areas and the nature of the strata. It is also important that the nature and occurrence of ground water be investigated. If the standing levels of ground water vary from stratum to stratum or if there is a water table gradient between boreholes this needs to be noted. Chemical analysis of samples of groundwater and soil should be performed to determine the constituents in ground water and soil that may contain harmful constituents in amounts sufficient to cause damage to Portland cement concrete or buried reinforcement. BS 8004 also specifies that the design of piles shall take into account of the factor of safety against failure, the settlement of the foundation as a whole and in differential settlements under working load, and the safety and stability of nearby buildings and services [3].

The building working load that gets transferred to the pile foundation is eventually distributed to the ground soil and bed rock by means of: (1) 
skin friction; developed by the interaction between the pile circumferential surface and soil and (2) end bearing; developed by the resistance between the pile end and the bed rock to which the pile is generally socketed. Although the codes specify a high safety factor for piles since this is an underground construction, designer's intended pile capacities will not be achieved unless the quality control of the installation is properly carried out.

Since, testing of each pile by static load test or by dynamic load testing is very costly and a time consuming process, the only measure of assuring the quality is to carryout load test on 5$10 \%$ of the total number of piles. Presently the selection of piles for load testing is arbitrarily carried out without considering all the factors that cause a pile to fail during installation. Thus, there is a need to improve the present quality assurance system to ensure a safe pile foundation system.

\section{What are the factors that affect the quality of piles?}

\subsection{Quality of Drilling Machines and Drilling tools}

There are many types of machinery for drilling a pile. Try-pod type percussion drilling tools, Machine mounted tools and Drilling Rigs etc. Machinery and tools depend on the type of soil, type of rock, pile diameter etc. Capacities of the different machinery and the quality of the tools are also factors that affect the quality of the drilling process. Since hard rock in Colombo is found at shallow depths like $20-30 \mathrm{~m}$, most designers tend to specify the pile to socket into the hard rock which has an allowable bearing capacity of $3000-5000 \mathrm{kN} / \mathrm{m}^{2}$. Thus to penetrate these rocks we need to utilize proper drilling tools and machinery to achieve the specified penetrations. A defective drilling tool could lead

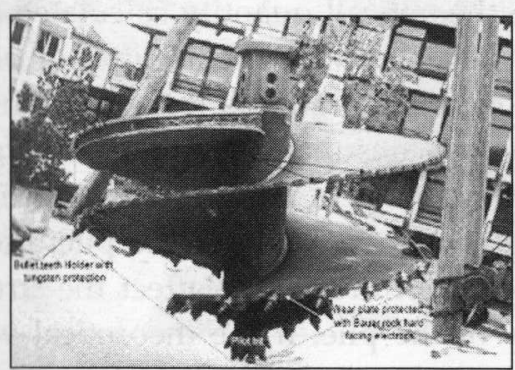

Figure: 2a Rock auger used to drill through rock to improper coring (Fig.2a and Fig.2b). The quality of the pile depends on tools and Machinery that are used for installation.

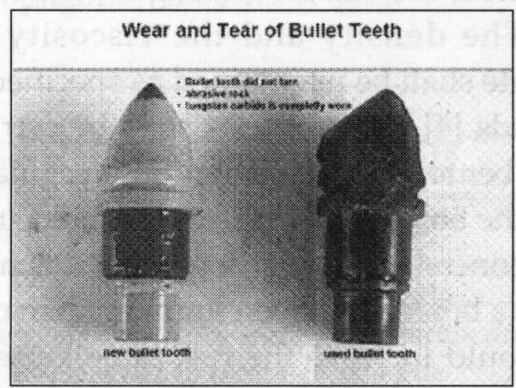

Figure $2 b$ : Wear and Tear of Bullet teeth

\subsection{Quality of rock socketing}

Identification of the hard basement rock is always a debating point between the piling contractor and the Engineer. In-order to transfer building loads down to the rock, piles shall be socketed in to the hard basement rock. If the designer had assumed an allowable end bearing capacity of $5000-3000 \mathrm{kN} / \mathrm{m}^{2}$, then the RQD values of the hard basement rock could be in the range $75-50 \%$, respectively.

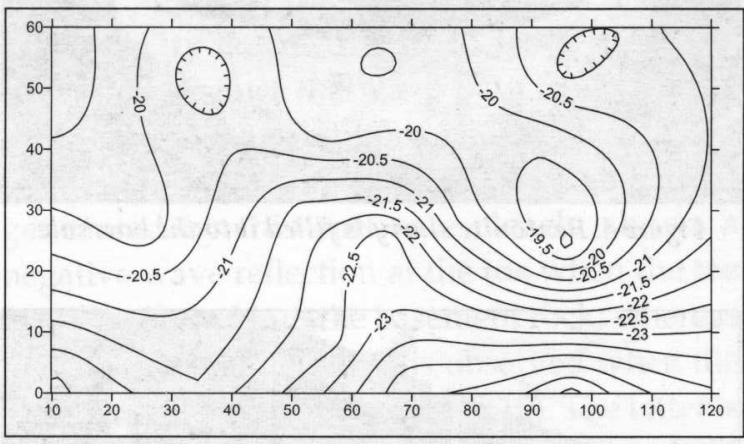

Figure: 3 Typical contour map of basement rock

Thus, it is a very difficult task to assume the RQD values by the observation of the samples obtained from the boreholes. The Authors propose to draw contours using the available borehole data and bore first piles very close to boreholes and measure the rate of penetration in different rock strata. These contours can be used to predict the hard basement rock layer in the proposed site of construction (Fig.3).

\subsection{Quality of Maintaining Borehole}

Skin friction capacity of the pile is governed by the stiffness of the soil which embraces the pile. Thus, it is very important to keep the borehole walls intact until the concrete is placed. The key material to maintain and stabilize the borehole 
against collapsing, in the case of uncased piles, is the drilling fluid. The Drilling fluid may be bentonite slurry or Polymer (Fig.4). In Sri Lanka, bentonite is used as the drilling fluid most of the time. The density and the viscosity of the bentonite shall be maintained as specified in the standards [4]. Control tests shall be carried out on the bentonite suspension on a regular basis inside the bore and in the storage tanks until the pile is concreted (Fig.5). In general it is not wise to keep a bored hole open for more than one day as it would increase the risk of collapse of the borehole wall. However, under practical situations boreholes may have to be kept open for more than two to three days; perhaps for weeks. Do we consider this factor for the pile test selection criteria?

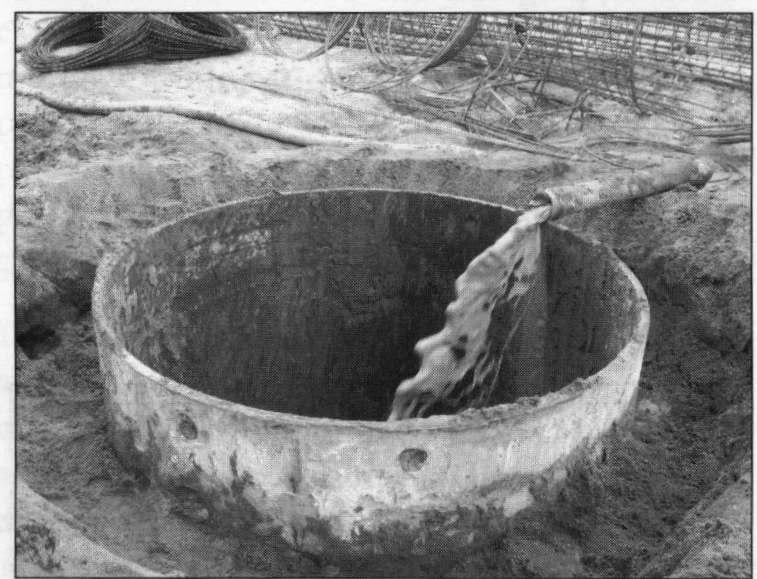

Figure 4: Bentonite slurry is filled into the borehole

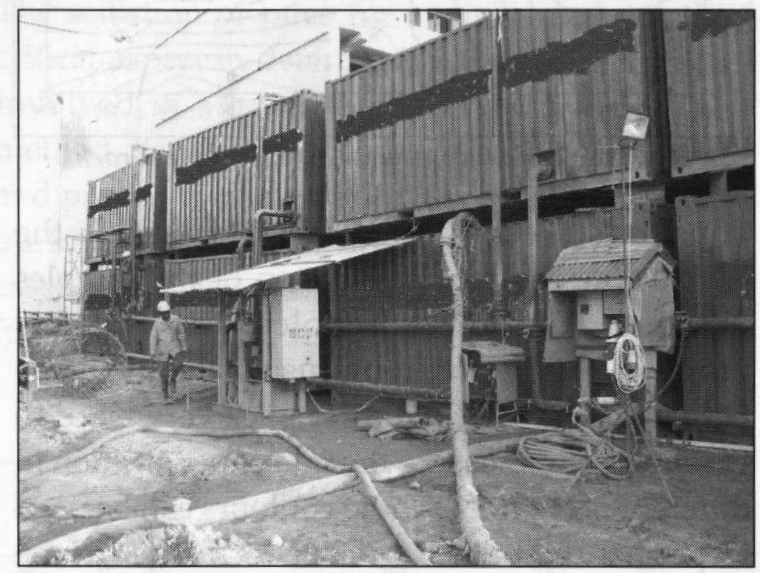

Figure 5: Bentonite Storage tanks

\subsection{Quality of Cleaning the Borehole}

Before placing the concrete, measures shall be taken to ensure that there is no accumulation of silt or other material and heavily contaminated drilling fluid, which could impair the free flow of concrete from the pipe of the tremie at the base of the bore. Cleaning of the base of the bore can be done by flushing the bore using fresh bentonite under pressure. For large diameter piles (1200 mm or more) a de-sander can be used to clean the pile bore (Fig.6). If the piles are not cleaned properly there will be a soft toe condition which in turn will cause a reduced end baring capacity of piles and will lead to large settlements under service conditions. Thus, do we account for the quality of cleaning of the base for the pile test selection criteria?

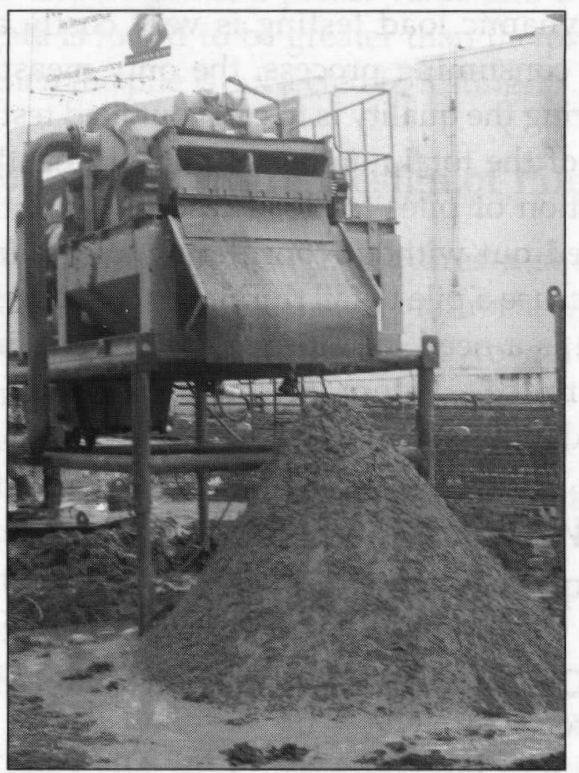

Figure 6: De-sanding process

\subsection{Quality of Concreting}

Structural capacity of the pile is based on the quality of the concreting procedure and the concrete itself. Since the concrete in the borehole is compacted by itself, the concrete needs to possess cohesiveness (resistance to segregation) and flow ability. A Tremie pipe of $150-200 \mathrm{~mm}$ diameter shall be used to place concrete to avoid segregation and the bottom of the tremie must stay well below ( $2.0 \mathrm{~m}$ minimum) the top of the column of fresh concrete at all times. However in practice there will be a difference between the actual concrete quantity consumed by the pile and the theoreticall quantity calculated for the pile. This difference can be negative or positive. If the theoretical value is less than the actual quantity it means that there may be bulging in the pile shaft where it may reduce or increase the skin friction capacity of the pile; however, this would not drastically affect the structural capacity of the pile. If the theoretical value is more than the actual value, there may be 
necking in the pile which in turn will give rise to the reduction in the structural capacity of the pile. The other factor that the Engineer will check on concrete is the cube strength of the concrete. Are these factors considered during the test selection process?

\subsection{Integrity of the Pile}

How well the pile is constituted with the concrete and reinforcement and is properly socketed into the basement rock will decide the pile's ability to carry the design load. The integrity of the pile is largely dependent upon the factors discussed in sections 3.1 through 3.5. An adequate inspection to verify the integrity of the pile shaft would enhance the level of confidence of the Engineer in terms of the load bearing capacities of the piles. Pile Integrity Testing, largely known as PIT is a procedure for quality assessment of cast-in-place piles using the low strain pulse echo method (Fig. $7 a$ and Pig. $7 \mathrm{~b}$ ). This method provides a quick and relatively inexpensive means to assess the

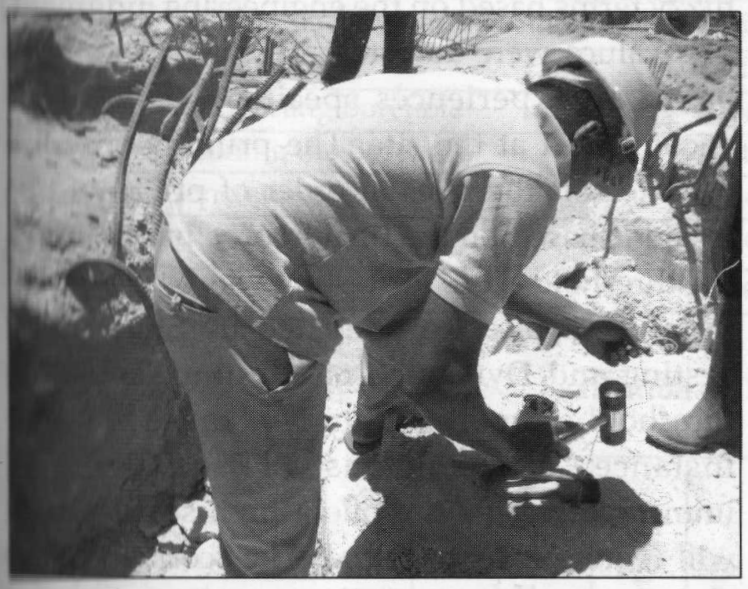

(7a)

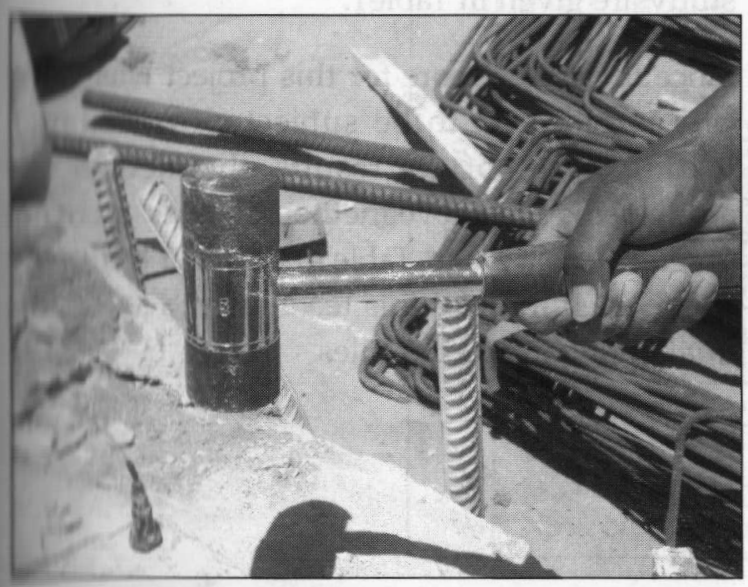

(7b)

Figure $7 a \&$ \& $7 b$ Pile Integrity Testing integrity of piles. The wave motion generated by the impact of a small hand held hammer on the top of the pile is studied using one dimensional wave propagation theories (Fig.8).

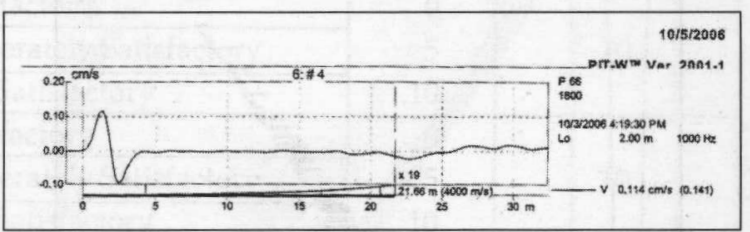

Figure 8: Typical velocity wave propagation diagram from PIT of a cast-in-situ pile

The pattern of wave speed generated in PIT can be studied thoroughly to investigate the presence of necking, poor quality concrete, bulging, cavities etc. and the location of such defects in the pile shaft. Also, one important observation made in our study using PIT was the identification of the soft toe condition, which is the primary cause for reduced end baring capacities of piles and large settlements under service load conditions. A soft toe condition occurs mainly due to improper cleaning and flushing of the pile toe.

The velocity curves obtained from PIT were compared against the wave pattern generated for different toe conditions using the software "Pilewave", version 3.0.0 [5]. The wave pattern generated by this software clearly shows a negative wave reflection at the toe when the toe is well socketed into the basement rock; whereas a positive wave reflection is observed when the toe is unsocketed (Fig. 9 and Fig 10). The latter is analogous to a soft toe condition. Thus, PIT results with such a wave pattern could suggest a soft toe condition. This reasoning is convincingly supported by Jayasinghe [6] in his book on Pile Integrity Testing and Dynamic Pile Testing.

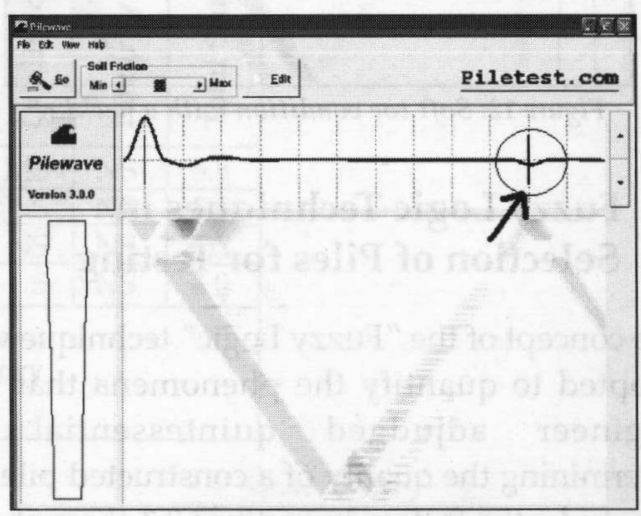

Figure 9: Well socketed pile 


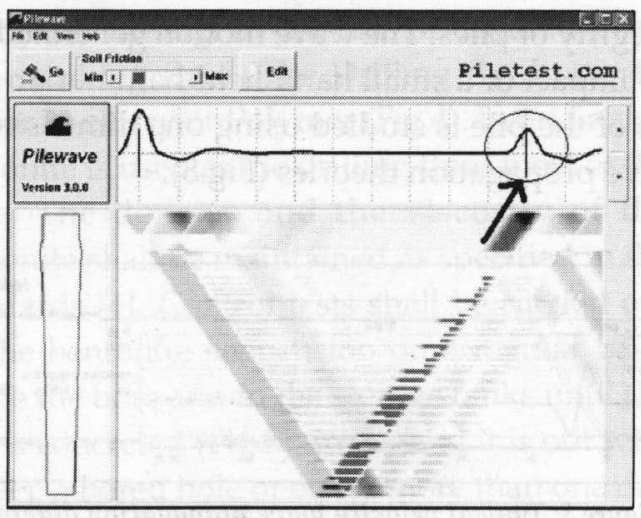

Figure 10: Pile with soft toe condition

A further investigation showed that when a positive reflection or the reflection of the same sign as the input wave is encountered, a necking or defect (not necessarily) could be expected at that location of the pile (Fig 11, Fig 12 and Fig.13).

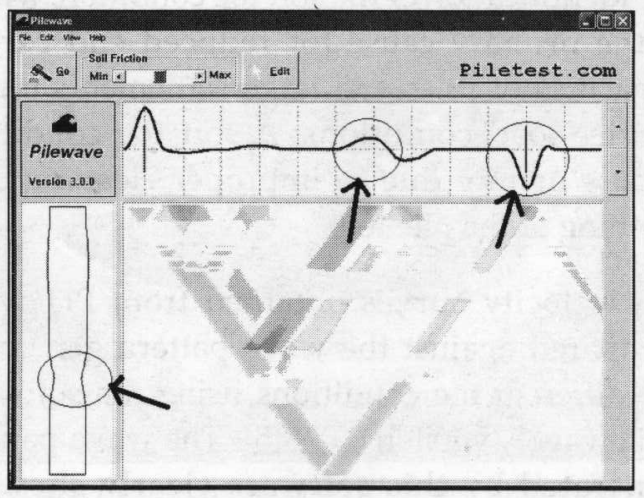

Figure 11: Well Socketed pile with a necking

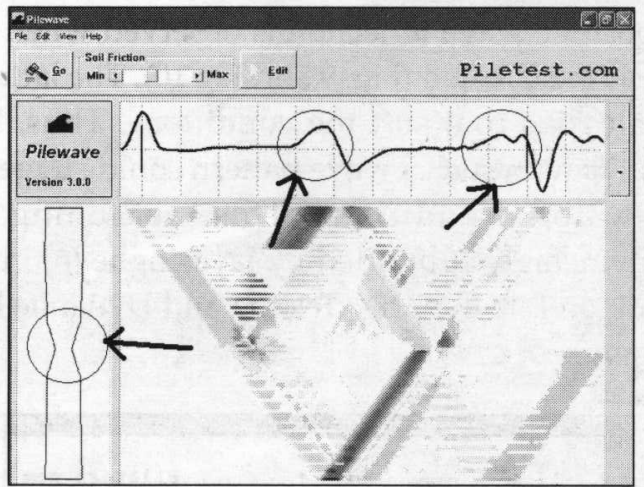

Figure 12: Soft toe condition with a necking

\section{Fuzzy Logic Techniques in Selection of Piles for Testing}

The concept of the "Fuzzy Logic" technique was adopted to quantify the phenomena that the Engineer adjudged quintessential in determining the quality of a constructed pile. In our study, the factors in sections 3.1 through 3.6 were selected to quantify the degree of non confidence of a pile. The fuzzy logic is a computing technique, which can quantify the expert's judgement. This system can help model or control a system when we do not have a mathematical model of how the system's output depends on its input [7].

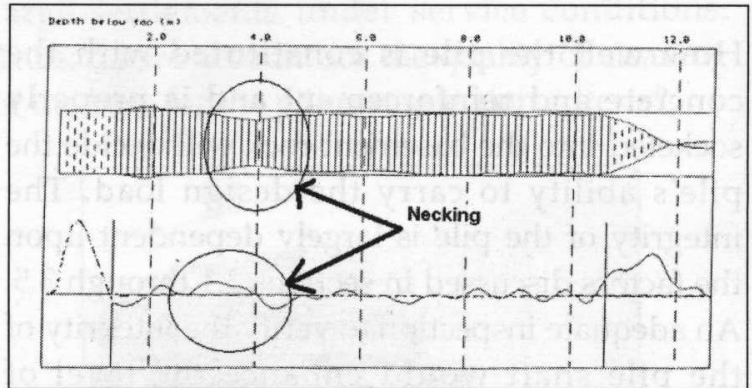

Figure 13: The velocity propagation curve for a pile with a necking

Linguistic variables such as "Satisfactory", "Moderately Satisfactory", and "Not Satisfactory" were defined for various factors discussed in section 3.1 through 3.6 and a weighting system was assigned to each of these fuzzy terms based on the engineering judgment. The values were adjusted as piling progressed based on experiences specific to conditions encountered at the site. The primary criterion used to sort the piles in order of priority to be tested is based on the final 'score'. In our study, the threshold score for testing was based on the number of piles to be tested by Static Load Testing and Dynamic Load testing. Thus, the threshold score in our study was set to 4 . For instance, a suspicious PIT results will immediately give the pile a high score, which will require it to be tested. The scoring system and the respective weightings adopted in our study are given in Table1.

Since the preset score for this project was 4 , the pile is required to be subjected to dynamic testing. Some of the results obtained in our study using the above method of assessment are given in Table 3 and Table 4 . This is a testimony to the usefulness of this technique to assess the quality of constructed piles. 
Table 1: Assigned Scores and Weightings

\begin{tabular}{|c|c|c|c|}
\hline Description & Linguistic Variable & Score & Weighting $(\%)$ \\
\hline \multirow{3}{*}{ Quality of Drilling Machines and Drilling tools } & Satisfactory & 0 & \multirow{3}{*}{5} \\
\hline & Moderately Satisfactory & 5 & \\
\hline & Not Satisfactory & 10 & \\
\hline \multirow{3}{*}{ Quality of rock socketing } & Satisfactory & 0 & \multirow{3}{*}{10} \\
\hline & Moderately Satisfactory & 5 & \\
\hline & Not Satisfactory & 10 & \\
\hline \multirow{3}{*}{ Quality of Maintaining Borehole } & Satisfactory & 0 & \multirow{3}{*}{10} \\
\hline & Moderately Satisfactory & 5 & \\
\hline & Not Satisfactory & 10 & \\
\hline \multirow{3}{*}{ Quality of Cleaning the Borehole } & Satisfactory & 0 & \multirow{3}{*}{15} \\
\hline & Moderately Satisfactory & 5 & \\
\hline & Not Satisfactory & 10 & \\
\hline \multirow{3}{*}{ Quality of Concreting } & Satisfactory & 0 & \multirow{3}{*}{20} \\
\hline & Moderately Satisfactory & 5 & \\
\hline & Not Satisfactory & 10 & \\
\hline \multirow{3}{*}{ Integrity of the Pile } & Satisfactory & 0 & \multirow{3}{*}{40} \\
\hline & Moderately Satisfactory & 5 & \\
\hline & Not Satisfactory & 10 & \\
\hline
\end{tabular}

An example of evaluating the final score of a pile for selection for testing is given in Table 2.

Table 2: Example of the Method of Assessment of a Pile

\begin{tabular}{|l|l|c|c|c|}
\hline \multicolumn{1}{|c|}{ Description } & Linguistic Variable & Score & $\begin{array}{c}\text { Weighting } \\
(\%)\end{array}$ & Final Score \\
\hline Quality of Drilling Machines and Drilling tools & Satisfactory & 0 & 5 & 0.0 \\
\hline Quality of rock socketing & Satisfactory & 0 & 10 & 0.0 \\
\hline Quality of Maintaining Borehole & Moderately Satisfactory & 5 & 10 & 0.5 \\
\hline Quality of Cleaning the Borehole & Not Satisfactory & 10 & 15 & 1.5 \\
\hline Quality of Concreting & Moderately Satisfactory & 5 & 20 & 1.0 \\
\hline Integrity of the Pile & Moderately Satisfactory & 5 & 40 & 2.0 \\
\hline & Total Score & & 5 \\
\hline
\end{tabular}

Table 3: Evaluation of Piles Based on Fuzzy Logic Technique

\begin{tabular}{|c|c|c|c|c|c|c|c|}
\hline $\begin{array}{l}\dot{0} \\
\dot{z} \\
\dot{a}\end{array}$ & 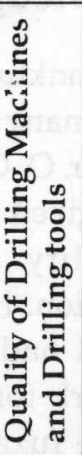 & 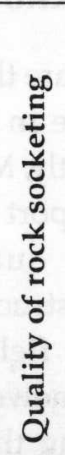 & 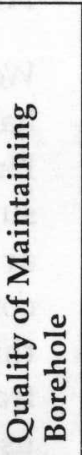 & 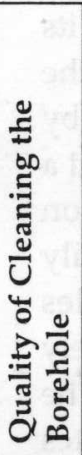 & 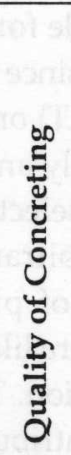 & 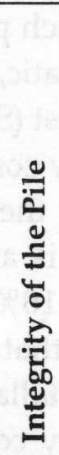 & $\begin{array}{l}\text { : } \\
\text { फू } \\
\frac{\pi}{0} \\
0\end{array}$ \\
\hline P49 & $S$ & $S$ & MS & S & MS & NS & 5.5 \\
\hline P114 & $S$ & $S$ & $\mathrm{~S}$ & NS & $\mathrm{S}$ & NS & 5.5 \\
\hline P123 & $S$ & $S$ & MS & $\mathrm{S}$ & NS & NS & 6.5 \\
\hline P142 & $S$ & $S$ & $S$ & $S$ & $S$ & NS & 4.0 \\
\hline Note: & \multicolumn{7}{|c|}{$\begin{array}{l}\text { S - Satisfactory } \\
\text { MS - Moderately satisfactory } \\
\text { NS - Not Satisfactory }\end{array}$} \\
\hline
\end{tabular}


Table 4: PIT and PDA Results of Selected Piles

\begin{tabular}{|c|c|c|c|}
\hline \multirow[t]{2}{*}{ Pile No. } & \multirow[t]{2}{*}{ PIT Results } & \multicolumn{2}{|c|}{ PDA Results } \\
\hline & & $\begin{array}{l}\text { Test Load } \\
\text { (Tons) }\end{array}$ & $\begin{array}{c}\text { Mobilized } \\
\text { Capacity } \\
\text { (Tons) }\end{array}$ \\
\hline P49 & $\underbrace{0.0260}_{5}$ & 2569.5 & 1311 \\
\hline P114 & 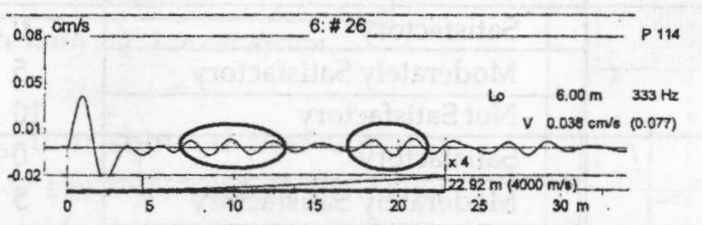 & 2569.5 & 1537 \\
\hline P123 & 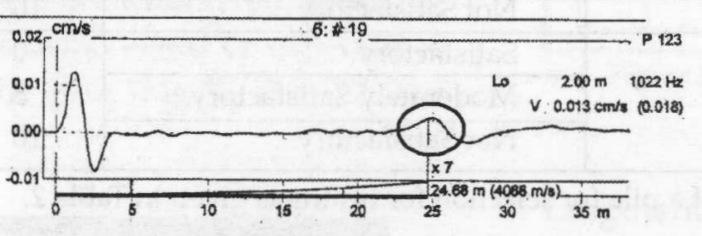 & 2569.5 & 1124 \\
\hline P142 & 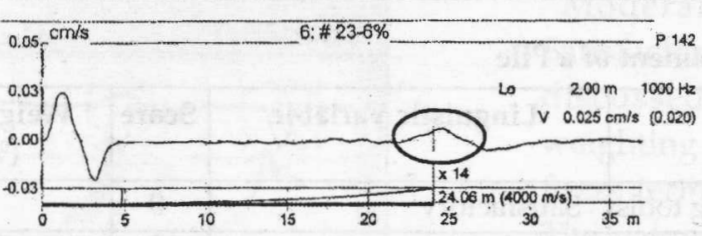 & 2569.5 & 1137 \\
\hline
\end{tabular}

\section{Conclusions}

The consequences of a pile failing could prove atrocious to the owner of the building. Therefore, a proper QA/QC plan needs to be in place to ensure, piles, preferably all the piles, are checked against the expected design parameters. However, testing of each pile for its load bearing capacity is not pragmatic, since the testing of each pile by static load test (SLT) or by dynamic load testing (PDA) is very costly and a time consuming process. Presently the selection process of piles for load testing is arbitrarily carried out on approximately $5-10 \%$ of piles without considering all the factors that are likely to cause failure of piles during installation. The arbitrary selection of piles possibly contributes to the high cost and time involvement in quality assurance and control systems.

The degree of confidence with a constructed pile is essentially unquantifiable as there are various unknowns involved in the factors discussed in sections 3.1 through 3.6. Our study focused on developing a technique to quantify the degree of confidence of a pile by considering the critical factors that are involved in the construction of a pile. The method devised in this study to select piles for dynamic testing had proven extremely effective and efficient

\section{Acknowledgement}

We are thankful to a number of individuals, who have in many ways contributed to this study. Firstly, Mr. O. C. Jayawardane, for his unfettered support given to us in developing a state-of-theart quality monitoring system in pile construction. His knowledge and experience in this field had facilitated us in developing a framework for the quality monitoring system using the fuzzy logic technique. We are, also, grateful to Eng. T.P.G.U.Alwis for his support in gathering information from various sources and making this available to us along with the necessary technical software for the assessments. We are obliged to Eng. Dr. A. C.Visvalingam, Eng. K. L. S.Sahabandu and Eng. Mahesh Gamage for their valuable encouragement and advice on piling works. 


\section{References}

1. http://www.bauer.de

2. Singapore Standard, CP 4 :2003 (ICS 91.040; 93.020), Code of Practice for Foundations, SPRING Singapore.

3. British Standard, BS 8004: 1986, Code of Practice for Foundations, British Standards Institution.

4. Specification for Piling, Table 5.1, Institute of Civil Engineers London.

5. http://www.piletest.com

6. L.P.Jayasinghe, Pile Integrity Testing (PIT) and Dynamic Pile Testing (PDA), Geotech Testing Services (PVT) Ltd.

7. Bart Kosko, Fuzzy Engineering, Prentice Hall. Inc, 1997, USA. 